\title{
Adoptable Solution on Financing: Using Crowdfunding Platform in Urban Regeneration Planning
}

\author{
JuYoung Park ${ }^{1}$, SeoYoun Choi $^{2}$ and Kabsung Kim ${ }^{2}$ \\ ${ }^{1}$ Yonsei Graduate School of Engineering interdisciplinary studies \\ ${ }^{2}$ The Graduate School Yonsei University Department of Urban Planning and Development
}

\begin{abstract}
Today, most local governments are facing considerable financing problem but the needs of the people have not subsided, segregation of neighborhoods and neglected urban spaces still permeate our cities. Finding new ways to raise capital becomes an important task to continue the urban regeneration, rehabilitation. In political, academic and market circles, as solutions compatible with the desire of communities and sustainable development, local and regional governments have increasingly seeking solutions as a way to solve financial problems. Crowdfunding has been used by market as a revolutionary form of raising capital, using social networking, forming large pools of small investors. By adjusting its method to urban regeneration planning it may become possible to fulfill the needs of financing, the community and governments. This may bring a sense of greater public participation and exact knowledge on crowdfunding of social meaning. The aim of this paper is to discuss on the ways of this concept of crowdfunding in urban rehabilitation can help both society and economy.
\end{abstract}

Keywords: crowdfunding, urban planning, urban regeneration, public participation, financing methods.

\section{Introduction}

\subsection{Emerging Paradigms of Urban Regeneration}

Urban regeneration has been increasingly a part of public policy, central government sponsored gentrification as a process to regenerate the urban environment has long been accepted by both public and business as a part of a wider strategy through economic development. Public spaces may be as useful components of these strategies and assist in improving an areas and gathering communities.

Property led regeneration such as infrastructure and abandoned developments or underused office, commercial or anchor residential. This tendency points out that the approach fails to address social issues and sustainable rehabilitation city.

In the past decade the spread of internet technology have created new business models and reshape our economy. Creativity and collaboration is needed to solve various challenges. A mechanism for collective action where we as people band together to make laws, pay taxes and build the institutions required to solve the complex problems arising from our collective life. (O'Reilly, 2011). The government will use technology, particularly the internet and mobile phone, to engage its citizens in the collaborative solving of the problems that affect it at all levels. Local, regional, national and even international and particularly social networks will enable us to build a participatory government with a more direct democracy. This participation in urban planning is fast becoming a reality. In the United Kingdom, for example, community involvement has become a central element in urban planners but the question now becomes how to effectively implement it given its many difficulties.

\subsection{Current Issues on Local and Regional Government}

Local governments plan expenditures on a variety of services including policies, protection, education and social welfare expenditures, housing and etc. They fund services and the make infrastructures associated with 
residents to prosper cities. Local governments grappling with the effects of the global financial crises face various constraints that although different in nature have a cumulative effect on their financial health (Paulais, 2009). Similarity between Japan governments and Korea governments describe government finance as in difficult situation. For years, central governments and local governments have been on an unsustainable financial plan with declining revenues.

\subsection{The Financial Crisis on Global Market}

Rising defaults in the subprime mortgage market combined with stalled home appreciation quickly materialized into losses of highly leveraged investors. (Mauboussin, 2007) The market investors, spurred by low returns in the bond market, higher yields in the housing market and the ratings of credit agencies had snapped up gigantic amounts of lower quality mortgage backed for securities. In the final phase, lenders begin to raise collateral requirements but as the asset prices dip lenders require huge more capitals as collateral forcing investors to sell assets further depressing prices. The additional price drop spurs margin calls and the positive feedback loop. It became out of control affecting all classes of assets held by under-duress investors whether unrelated to the housing market or not.

\subsection{Issues for Private Enterprise}

Private real estate companies have also found it increasingly difficult to finance their new investments and ongoing developments in the countries most affected by the financial crises or sovereign debt issues. The Ongoing developments halted and new developments were abandoned. Today the number on concern for small to medium size-companies is raising credit, even though they are profitable and are growing. Sovereign debt problems reflect negatively on the private sector of the affected country, if the government can repay its debts and needs to restructure them the ability to raise credit from foreign capital markets is greatly reduced for private sector companies. In some countries a bloated construction sector contracted so much debt and contributed to such a big percentage of jobs and growth that its contraction has sent unemployment levels to massive numbers (Smyth, 2013). Banks, on the top of other problems brought about by the financial crisis on global market, have been repossessing homes from families that cannot pay their loans. This has created issues for banks as properties pay taxed and they cannot afford to keep these properties on their balance sheets for ever, particularly when they are going down in value

\subsection{Crowdfunding}

\subsubsection{Definition}

Definition of crowdfunding is a new process of funding ideas or projects(even charitable cause) by raising money from large numbers of individual donors. As a collective effort of many individuals who network and pool their resources to support efforts initiated by other people or organizations. This is usually done via or with the help of the internet. Traditionally, financing a business or project involved asking a few companies and people for large investment. Every company has funding gap on managing. This state is called as "Death Valley". Crowdfunding may have become an alternative financing method to solve the fund ongoing operation. However, individual projects and businesses are financed with small contributions from a large number of individuals, allowing innovators, entrepreneurs and business owners to utilize their social networks to raise capital. 


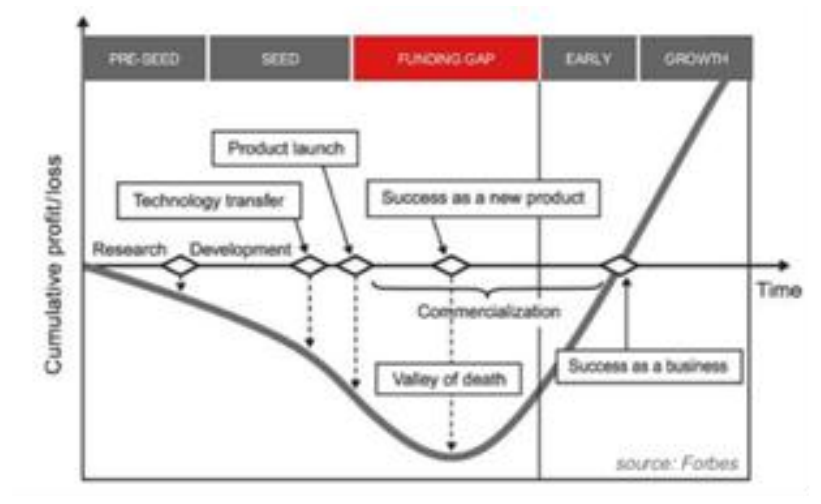

Fig. 1: Funding Gap and Valley of Death

\subsubsection{Why Adopting Crowdfunding}

Why are entrepreneurs adopting this new way of funding? We must also look at the types of endeavours being funded through crowdfunding platforms. The various types of crowdfunding platforms available will be discussed and varied that we can't generalize. Why the entrepreneurs are looking towards crowdfunding to finance their ventures? Motivation behind project funders can be of three types: social, material and financial. With social returns the funders have an intrinsic motivation and the fulfilment of the project is the reward they are seeking. Material returns are associated with product driven ventures. Financial returns are motived when a funder is ought to seek for the financial returns in addition to support the project or earn equity. Above these three types of the motivation can also define the models of crowdfunding. Generally, crowdfunding are specified in 4 different types

- Donation: a donor contract without existential reward

- Reward : purchase contract for some type of product or service.

- Lending: credit contract, credit is repaid plus interest.

- Equity: shareholding contract, shares, equity-like instruments or revenue sharing in the project/business potential up-side at exit.

\section{Case Studies}

\subsection{Glyncoch Community Centre in British}

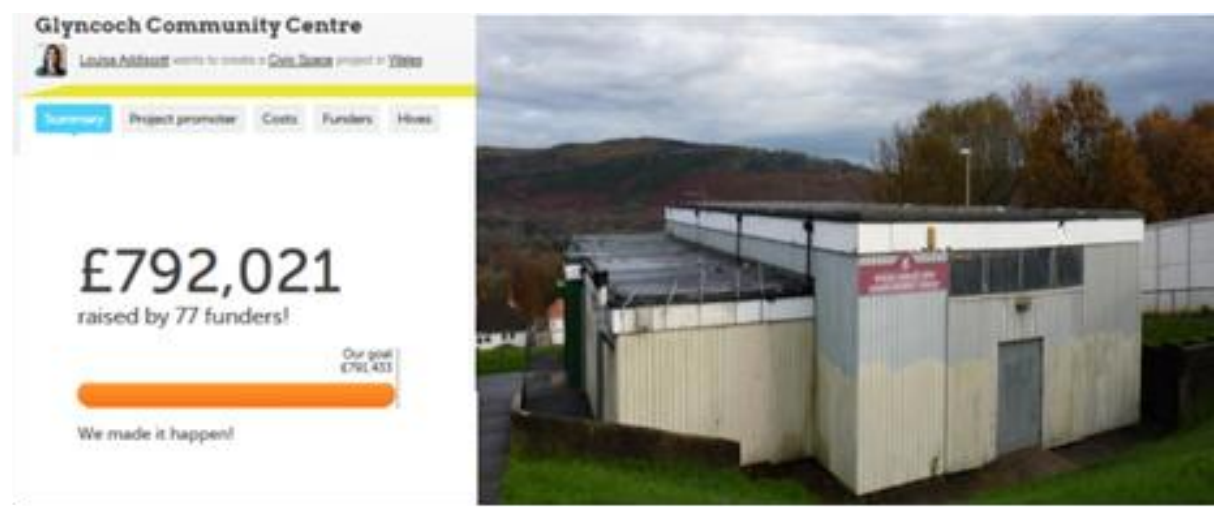

Fig. 2: Glyncoch Community Centre

For example, Those who have willingness to make donation through the crowdfunding exist and furthermore they not only make interest but also the community network. It is very difficult for investors to put down money in unknown market but the local community would make them believe safe by familiar environment. The Glyncoch community center project involves building a new multi-purpose community center. Workshops, 
community groups, conference suites for local businesses and the cycle of abandon area. The campaign was successful in raising funds up to $800 \mathrm{f}$ from various funders. The government' $\mathrm{s}$ fund pledging the half of the total fund and the left half of money was granted by local and regional development funds.

\subsection{Financing, social equity on establishing Subway line number 9 in Korea}

Korea national government with a weak financial structure, the prospects for affordability and financial sustainability of finances required for subway construction is a critical standard of judgment than typical virtues such as financial efficiency or secondary virtues like transit share. This is a model in which citizens invest in Subway Line 9 bonds and receive profits higher than the interest rates of commercial banks. It is divided into 4, 5, 6 and 7 year-types depending on the period. It is possible to invest up to 20 million won per citizen, and the average rate of yield is set at about $4.35 \%$. In order to protect investors, Korea Financial Supervisory Service exercises supervisory authority, and mid-course sales were made possible. A total of 5,508 citizens joined the Citizen Fund. As can be seen in this case, the Citizen Fund has a number of possibilities and enormous implications.

TABLE I: Citizen Funding in Seoul Metro 9

\begin{tabular}{lllll}
\hline \hline Fund name & Group 1 & Group 2 & Group 3 & Group 4 \\
\hline Expire Date & 4years & 5years & 6years & 7years \\
\hline $1^{\text {st }}$ Goal interest\% & $4.13 \%$ & $4.23 \%$ & $4.34 \%$ & $4.44 \%$ \\
\hline $2^{\text {nd }}$ Goal interest\% & $4.19 \%$ & $4.29 \%$ & $4.40 \%$ & $4.50 \%$ \\
\hline \hline
\end{tabular}

TABLE II : Citizen Funding in Seoul Metro 9

\begin{tabular}{lllll}
\hline \hline Fund name & Group 1 & Group 2 & Group 3 & Group 4 \\
\hline Number of funders & 1,363 & 1,323 & 1,434 & 1,386 \\
\hline Average amount & 16,850 USD & 17,650 USD & 13,420 USD & 17,650 USD \\
\hline \hline
\end{tabular}

Source: Seoul local government, Korea Government 2014.8

\subsection{Considerable Factors of Adopting Crowdfunding on Urban regeneration}

- Peer-to-Peer Lending: used by borrowers looking for a lower interest rate, does not create new money

- Peer-to-business lending: equivalent to peer-to-peer but on a small and medium business scale

- Equity Crowdfunding: similar to business angels, investors are looking for some returns on their investment.

- Revenue Sharing: funders receive returns based of future revenue via revenue-sharing arrangement

According to crowdsourcing.org the primary revenue model for crowdfunding platforms is percentage based commissions on funds paid out to entrepreneurs. Risk assessment and related legislation are the obstacle that face crowdfunding are related with every type of business venture.

\subsection{Risk assessment}

Risk assessment is another problem in crowdfunding, its feature that the platform is open to many funders with the lack of knowledge with the exact definition in experiencing in financing venture business. However, interest arise from the crowdfunding is about $4 \%$ average. Unqualified investors who don't have their knowledge on business venture are able to manage their risk easily. To ensure that this is confined to the funders that may have more goals on social objects to achieve than the interest. Funders looking for their money value for the genuine donation on social welfare generate superior returns on themselves and the communities.

\subsection{Related legislation}

JOBS ACT in the United States had opened equity-based crowdfunding to unaccredited investors. This ACT did not lead to an immediate explosion in 2013 due to the Securities and Exchange Commision(SEC) had not yet drafted the necessary rules to comply with the ACT (Caldbeck, 2012; Clifford, 2013; Rosenberg, 2013) Legislation should either involve specific index on the crowdfunding market or not be defined narrowly. This may shed the new market on urban regeneration system. 


\section{Suggested Crowdfunding Models for Urban regeneration}

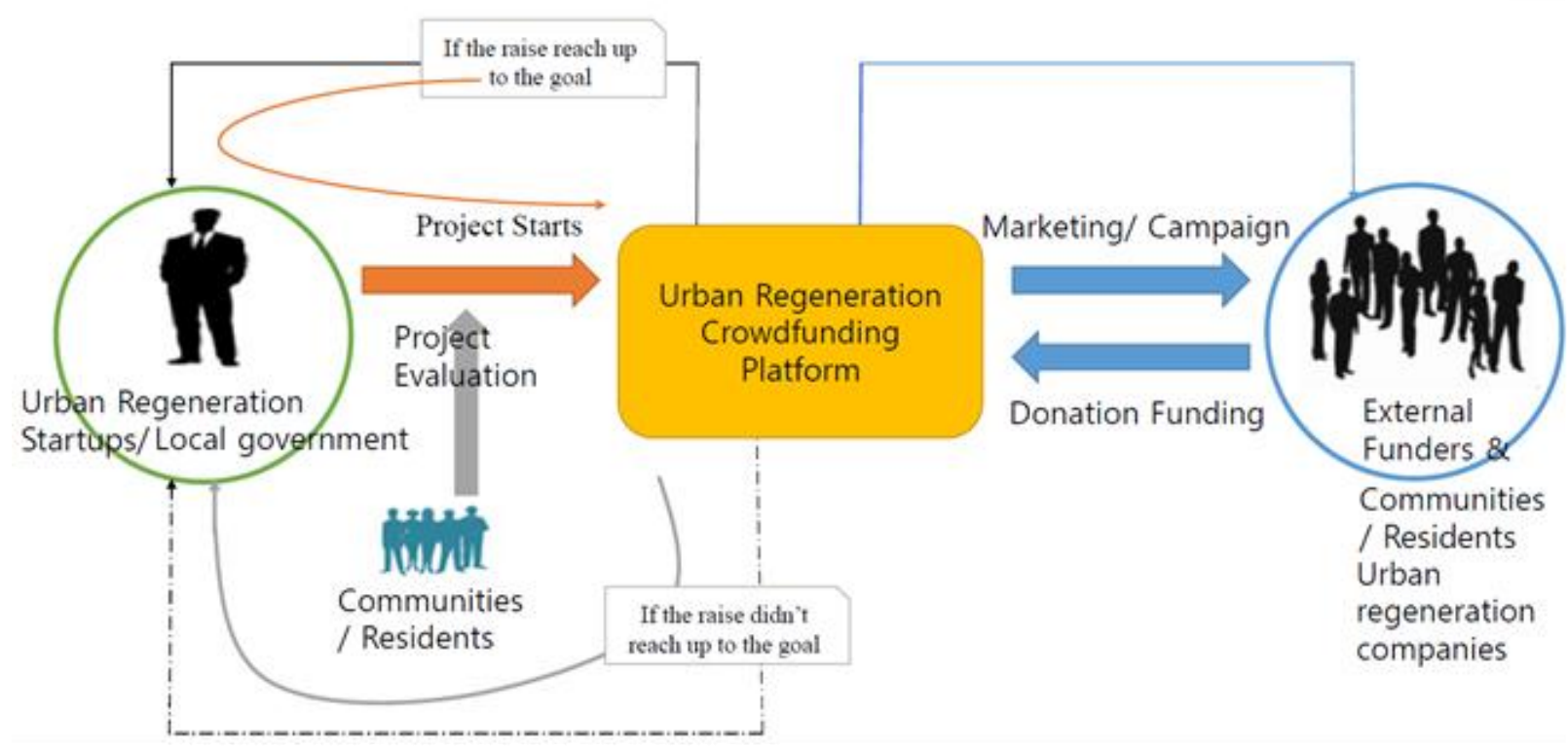

Fig. 3: Suggested Urban Regeneration Crowdfunding Platform

The project, if correctly handled by regulators, can create numerous new urban regeneration companies operating in a more localized and professionalized on urban rehabilitation venture. Innovative businesses that may be created and funded by the citizens and local government.

The funders may get projected financial returns are $4 \% \mathrm{ROI}$ (return on investment) due to the reason of the general average ROI on crowdfunding.

The new urban regeneration venture have to take the rights of ownership of the infrastructure or the service to sustain their management and grow size of the company.

The participant of the local community network various events shareholder parties, sports classes to reinforce network bondage. The property of the empty space or office should open to the local community members and also who do not invest on crowdfunding. This may get a second shot to enlarge the community member and lower the barrier to the entry to make next project on funding.

City government make taxation on regulation to make profits. Regional and local governments hold the power of licensing but there is a possibility that these innovative mechanism may break the difficulties on urban regeneration.

Crowdfunding can be integrated in practically in urban regeneration. Play a positive role in every sector(funders,companies,communities, governments).Municipalities is now become tools in small to large urban planning projects. This mechanism foster a direct relationship between residents and their environment. If citizens propose their own projects, public participation and dedication will rise by using crowdfunding and the fund from the government. Made platforms on this mechanism continuously give feedback in positive way and also interest in the urban environment. The maintenance expenditure could be seen difficult to generate enough but not all the projects and companies survive on the other market. This means that when locality meets the crowdfunding it could be fruitful both on economic sector and social sector. Funded projects as exampled, may not be the only suitable case good public conformity. These platforms have some drawbacks. As the constituents of the project remains their insistence, it could being cancelled or suspended during construction. This make all platform members troublesome when projects start construction because of the cost money in fines. To prevent these problems government involvement is necessary and concord of the communities, good recognition of their community is necessary. 


\section{Acknowledgements}

I want to appreciate collaborators who have helped me with the paper Yonsei Urban Planning Laboratory members and Professor Kim. Professor Choi who teaches Finance Information Technology gave latest information on financing. Also, researcher Ji Eun Lee for recommending this conference me in 2017 winter. I want to thank the members of interdisciplinary studies who inspired me to be the first person to write the papers for the abroad conference. Especially, send love to my family.

\section{References}

[1] O’Reilly, T., 2011. Government as a Platform. Innovations: Technology, Governance, Globalization 6, 13-40 https://doi.org/10.1162/INOV_a_00056

[2] Paulais, T., 2009. "Local Governments and the Financial Crisis: An Analysis. Cities Alliance",Washington.

[3] Caldbeck, R., 2012. "Crowdfunding Predictions for 2013”. Forbes.

[4] Smyth, S., Urban, R., 2013. "Spanish Banks Cut Developers as Zombies Dying: Mortgages”. Bloomberg.

[5] Mauboussin, Mi., 2007. Anatomy of a market crash. Forbes.

[6] J. P. Wilkinson, "Nonlinear resonant circuit devices," U.S. Patent 3624 12, July 16, 1990. (Patent style)

[7] Simon Cocking (January 24, 2017). Surviving the valley of death:Notes from a $3^{\text {rd }}$ year startup, lessons learned. Available: https://irishtechnews.ie/surviving-the-valley-of-death-notes-from-a-3rd-year-startup-lessons-learned/

[8] Do-Gyoon Kim (Feb 22, 2018). Ms.Min and Gamlin Funding Available: https://news.sbs.co.kr/news/endPage.do?news_id=N1004634815

[9] Crowd funding Glyncoch Community Centre. (October, 2014). pp. 4,11. Available: https://brick-work.org/wpcontent/uploads/2014/10/141021_GlyncochCommunityCentre1.pdf 